\title{
Comparative Analysis of Strong Convection Process of Convective Cold Cloud and Convective Warm Cloud Type
}

\author{
Yue Ni, Yuan Su*, Jinqin Feng \\ Longyan City Meteorological Bureau of Fujian Province, Fujian, China \\ Email: *suyuan4541@163.com
}

How to cite this paper: $\mathrm{Ni}, \mathrm{Y}$., Su, Y. and Feng, J.Q. (2018) Comparative Analysis of Strong Convection Process of Convective Cold Cloud and Convective Warm Cloud Type. Journal of Geoscience and Environment Protection, 6, 22-30.

https://doi.org/10.4236/gep.2018.69003

Received: July 9, 2018

Accepted: August 31, 2018

Published: September 3, 2018

Copyright $\odot 2018$ by authors and Scientific Research Publishing Inc. This work is licensed under the Creative Commons Attribution International License (CC BY 4.0).

http://creativecommons.org/licenses/by/4.0/

\begin{abstract}
On the night of April 20, 2017, there was a heavy rain in Longyan City, accompanied by strong convective weather such as strong lightning, short-term heavy precipitation, and $6-8$ thunderstorms. The three-hour rain intensity and the six-hour rain intensity of Shanghang Tongxian Township and Nanyang Town were once in a century. Through the use of radar, radar wind profile and lightning locator data, the process can be divided into two phases: The first stage is the strong precipitation stage of Changting Datong Town during the $20-22$ periods on the 20th. The process is accompanied by short-term heavy precipitation $(59.7 \mathrm{~mm} / \mathrm{h})$, strong lightning activity, and 6 8 thunderstorm gales. It is a convective cold cloud dominated precipitation. The second stage is the strong precipitation stage of Shanghang Tongxian Township on the 21st, $02-04$, and the short-term strong precipitation intensity reaches $75.7 \mathrm{~mm} / \mathrm{h}$, but the lightning and wind activity are weak, which is the convective warm cloud-oriented precipitation. There are significant differences in the strong convective weather between the two phases in the same background. The analysis shows that the strong echo of the first stage radar (above $60 \mathrm{dBz}$ ) is block-shaped southward, the speed of movement is fast, the height of the echo top is high, and the rear nascent monomer forms a train effect. In the second stage, the southwest-northeast-oriented convective zone moves to the northeast direction, forming the train effect of the echo zone. The center intensity is above $50 \mathrm{dBz}$, the echo top height is low, and the precipitation center moves slowly. This caused a large amount of accumulated rainfall. In this paper, the radar data is used to analyze the heavy rainfall process on the west coast of the straits, which has certain indication significance for the predictability of strong convective weather.
\end{abstract}

\section{Keywords}

Strong Convection, Convective Cold Cloud Dominated Precipitation, 
Convective Warm Cloud Dominant Precipitation, Oblique Pressure

\section{Introduction}

From the night of April 20, 2017 to the 21st, there was a heavy rainstorm in Longyan City. The precipitation process lasted for a short time, but the accumulated rainfall was large, and the local convection developed strongly. According to statistics (Figure 1), from 20 o'clock on the 20th to 20 o'clock on the 21 st, the city (excluding the traffic station) has a total of 52 regional stations with accumulated rainfall exceeding $50 \mathrm{~mm}$. There are 8 regional stations over $100 \mathrm{~mm}$, with $195.0 \mathrm{~mm}$ being the largest in Shanghang Tongxian Township and 192.1 $\mathrm{mm}$ in Nanyang Town. In terms of hourly rain intensity, there are 4 stations that reach $50 \mathrm{~mm} / \mathrm{h}$, and above Hangtong Xianxiang is $75.7 \mathrm{~mm} / \mathrm{h}$. In addition, the three-hour rain intensity of Shanghang Tongxian Township reached $151.2 \mathrm{~mm}$, the rain intensity reached $60.8 \mathrm{~mm}$ in 6 hours, the rain intensity in Nanyang Town reached $146.5 \mathrm{~mm}$, and the rain intensity reached $69.3 \mathrm{~mm}$ in 6 hours. The three-hour rain intensity and the six-hour rain intensity of these two stations were once in a century.

\section{Weather Scale Circulation Background Analysis}

There are high-altitude trough activities in the north and south of the $500 \mathrm{hPa}$ process. The bottom of the trough of the north branch trough gradually southward and has affected the area along the Yangtze River basin. The south branch trough gradually moved closer to the Longyan, and the southwest jet stream over the Longyan area was obviously strengthened. The southwest wind has strengthened into a hollow jet at 08:00 on the 21 st. This provides abundant water vapor and heat for strong convection development. In addition, a cold trough on the $500 \mathrm{hPa}$ gradually approaches the Longyan, bringing dry and cold air over the Longyan, providing a dry and wet stratification condition for the development of strong convection.

At $700 \mathrm{hPa}$, from 20 o'clock on the 20 th to 08 o'clock on the 21 st, the influence of the southwest jet flow control changed to the southward pressure of the shear system (Figure 2). At 20 o'clock, the significant cold and warm air at 500 $\mathrm{hPa}$ and $700 \mathrm{hPa}$ and $850 \mathrm{hPa}$ strongly intersected, resulting in oblique pressure front [1]. At 08 o'clock, with the shear change of $700 \mathrm{hPa}$, the shear system is gradually approached on 850 and $925 \mathrm{hPa}$. The three-layer shear position is almost vertical, and there is no obvious tilt, which provides better dynamic conditions for the generation of strong convection. At the same time, the $850 \mathrm{hPa}$ in Longyan area is an obvious wet area, which is between 14 and 16 than the wet. The $500 \mathrm{hPa}$ Shanglongyan area is located in the dry area. This dry and wet configuration provides better stratification conditions for strong convection.

In addition, there is an obvious jet stream diversion area at $200 \mathrm{hPa}$ over 


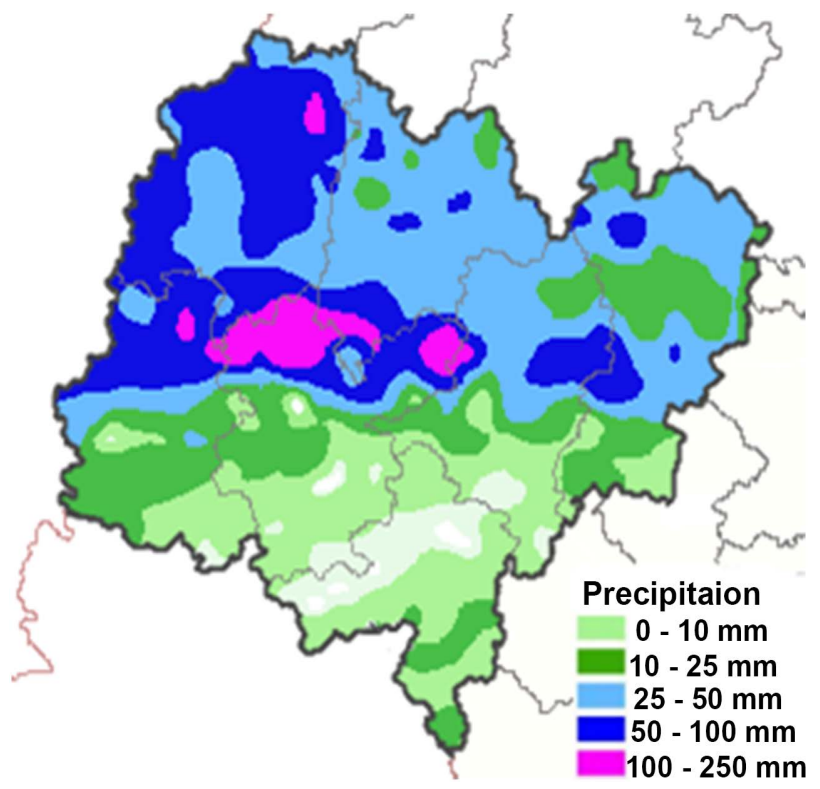

Figure 1. Accumulated precipitation in Longyan City from 20:00 on April 20 to $20: 00$ on the 21 st.
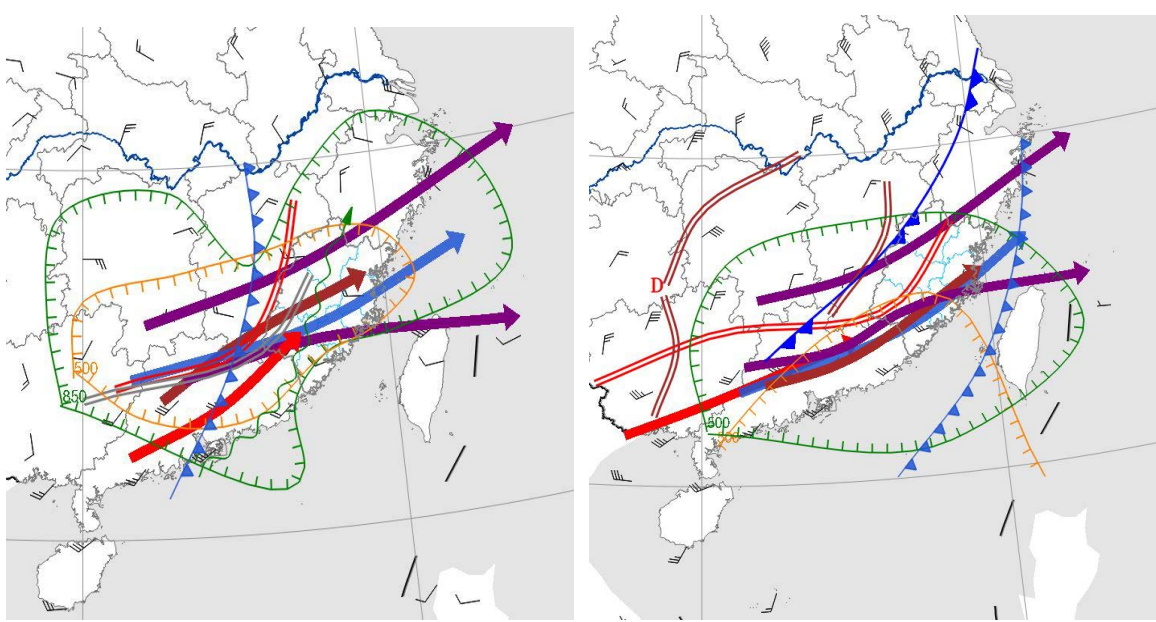

Figure 2. Analytical field at 20 o'clock on the morning of April 20, 2017 and 08 o'clock on the 21 st.

Longyan, resulting in obvious divergence over the area. The suction effect of this low-level convergence high-level divergence configuration further enhances the ascending motion of the region, providing favorable conditions for heavy precipitation. The ground gradually changes from low pressure back groove control to cold front south, providing a trigger mechanism for the occurrence of strong convection.

From the above background analysis of weather scales, it can be seen that the early stage of the process is in the stage of energy accumulation under the control of ground trough and low-level jet, and later into a systematic trigger stage under the situation of cold front and low-level shear southward. The conditions of water vapor and energy are the strongest in the early stage, and the dynamic 
conditions are the strongest in the late stage of the system. The weather scale background of the two stages is very favorable for the occurrence and development of strong convection [2].

\section{Local Precipitation Difference Analysis}

\subsection{Similarities and Differences between Local Precipitations}

Comprehensive analysis of satellite, radar, wind profiler radar and lightning locator data can be found. The main precipitation period of this process can be divided into the strong precipitation stage of Changting Datong Town during the 20 - 22 periods on the 20th and the strong precipitation stage of the Tonghang Township of Shanghang on the 21st. From the radar echo, the echoes in the first stage of the Changting moved mainly from the central part of Jiangxi to the southeast, forming a block-like strong single storm form southward and developing rapidly. In the second stage, the echoes are in the east-west direction, and the echo band moves eastward from the junction of Jiangxi and Guangdong. The direction of the echo zone is consistent with the direction of movement, resulting in a significant train effect [3].

In addition, from the evolution of the over-the-element elements of the station, Datong Town, Changting, accompanied the process of rapid pressure rise and sudden temperature drop in the event of short-term heavy precipitation, and the extreme wind of the station was also significantly strengthened. From the point of view of the lightning locator monitoring, it is also seen that there is obvious lightning activity, and all of the early stage is the case where the negative flash gradually turns into positive and negative flash [4] [5] [6]. Contrary to this, the short-term strong precipitation intensity of Shanghang Tongxian Township is very strong, but the changes in temperature, extreme wind and other factors are relatively more moderate, and the lightning activity is also very weak. The difference in precipitation properties between the two stations is very prominent. So why is there such a significant precipitation in the northern part of Changting and Shanghang in the same weather background, and why is the difference in precipitation properties between the two places so large?

\subsection{Analysis of the Causes of the Strong Precipitation in Changting and Shanghang}

\subsubsection{Local Wind Field Analysis}

From the radar echo, Changting continued to have new monomer developments. With the 10-minute wind analysis of the regional station, it can be found that the surface wind can analyze a local wind convergence center similar to the low vortex (Figure 3). The shear line can be analyzed in the southwest and northeast, respectively, and the local wind and wind convergence has been maintained for nearly half an hour. Contrary to Changting, when there was heavy precipitation in Tongxian Township, Shanghang (2:00 - 3 pm on the 21st), local wind convergence also occurred during this period, but only lasted for about 5 minutes. 


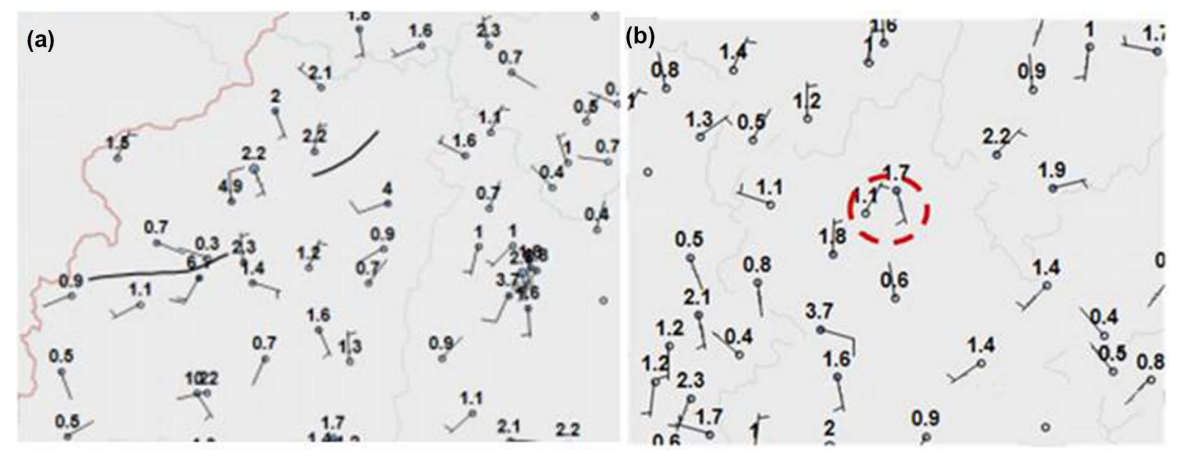

Figure 3. At 20:05 on the 20th, Changting County 10 minutes great wind (a) and Shanghang County Tongxian Township 02:15 minutes 10 minutes great wind (b).

\subsubsection{Analysis of the Influence of Cold Pool on Precipitation}

The formation of the cold pool is due to the evaporation of the surface precipitation and the relatively low temperature caused by the strong sinking of the dry cold air in the monomer storm. The edge of the cold pool is just a violent area where the sinking airflow and the ascending airflow at the front of the storm meet, thus facilitating the triggering and strengthening of the nascent monomer. From the distribution of the surface temperature in Changting County's strongest precipitation (20:00 - 22:00 pm on the 20th), the regional distribution below $21^{\circ} \mathrm{C}$ is in good agreement with the location distribution of strong precipitation and strong echo center. Moreover, the evolution of the strong echo center in many times is basically strengthening and moving along the edge of the cold pool. Therefore, the existence of the cold pool has a good effect on the strong precipitation in the Changting area. Similarly, the cold pool phenomenon was observed during the heavy precipitation in the Shanghang area [7].

\subsubsection{Analysis of the Influence of Cold Pool on Precipitation}

Judging from the terrain of Changting Station (Figure 4), it is surrounded by mountains on all sides. In the near view, there is a small mountain range running northeast-southwest in its southeast direction. As can be seen from the foregoing, the moving direction of the single storm is perpendicular to the direction of this small mountain range, causing severe ascending motion and convection triggering conditions, which is another driving reason for the rapid enhancement of the echo moving to the vicinity of Changting Station. Similarly, there is a small mountain distribution in the north-north direction of Shanghangtongxian Township. It coincides with the fact that the moving direction of the strong precipitation echo zone is orthogonal to the terrain, and it will also form a strong terrain uplifting effect.

\subsection{Analysis of the Differences of the Precipitation Echoes in Changting and Shanghang}

The previous article explains from the three aspects of local wind field convergence, topographical action and cold pool action why such a strong convective 


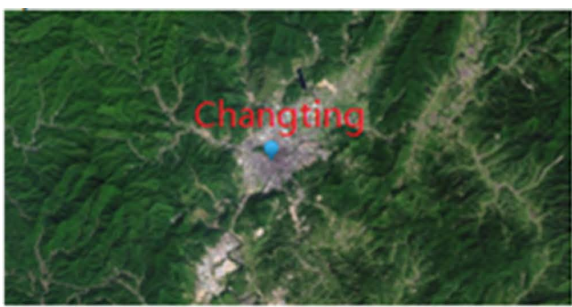

(a)

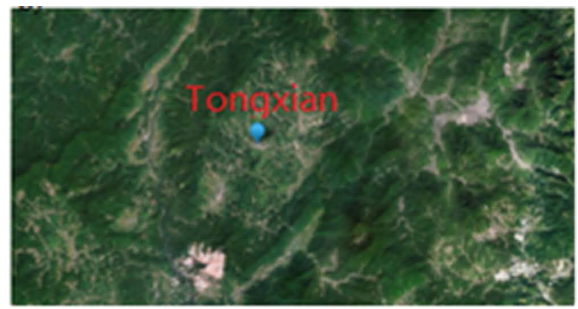

(b)

Figure 4. Distribution of topography around Changting County Station (a) and Shanghang Tongxian Township (b).

weather occurs only in Changting and Shanghang in the same circulation background. So why is the difference between the strong convective weather in these two places so obvious?

From the radar echo basic reflectivity factor product (Figure 5), it can be seen that from 19:55 to 20:07 on the 20th, the radar echoes over the Changting County Station are blocky, and the strong echoes develop to a higher altitude. Especially at the elevation angle of 1.5, the echo intensity reaches $60 \mathrm{dBz}$, and the strong center of the multi-elevation angle is basically at the same position, and no tilt occurs. And when the monomer storm moves over the site, there are new monomers moving through the station again, forming a train effect of the echo unit. In addition, it can be seen from the radial velocity (figure omitted) that a wind direction convergence zone is maintained for a long time in the Changting station, and the convection development is continuously stimulated [8]. In addition, it should be pointed out that while heavy precipitation occurred in the Changting area, there were $6-8$ thunderstorms in the towns and villages downstream of Changting, including $17.3 \mathrm{~m} / \mathrm{s}$ in Liuyuan Village and $18.6 \mathrm{~m} / \mathrm{s}$ in Xuanhe Township.

The radar echo characteristics of the occurrence of strong precipitation in Shanghang Xianxian show that from 14:00 to 2:29 on the $21^{\text {st }}$ (Figure 6), the echo center intensity is basically between $45-50 \mathrm{dBz}$, which is distributed in the east-west band. A strip-shaped echo train effect is formed at the station, and the strong echo center is maintained near the station for a long time. Different from the strong convection in Changting County, the strong echo center of Shanghang Tongxian Township has a tendency to tilt to the east when the strong precipitation develops. The intensity of the echo center is weak, and the strong lightning and thunderstorm winds are weak. The precipitation center has a slow moving speed and a long duration. The system moving speed and the monomer propagation cancel each other out, resulting in a large accumulated rainfall.

\section{Conclusions}

From the night of April 20, 2017 to the early morning of the 21st, short-term heavy precipitation occurred in Longyan Changting and Shanghang Tongxian 

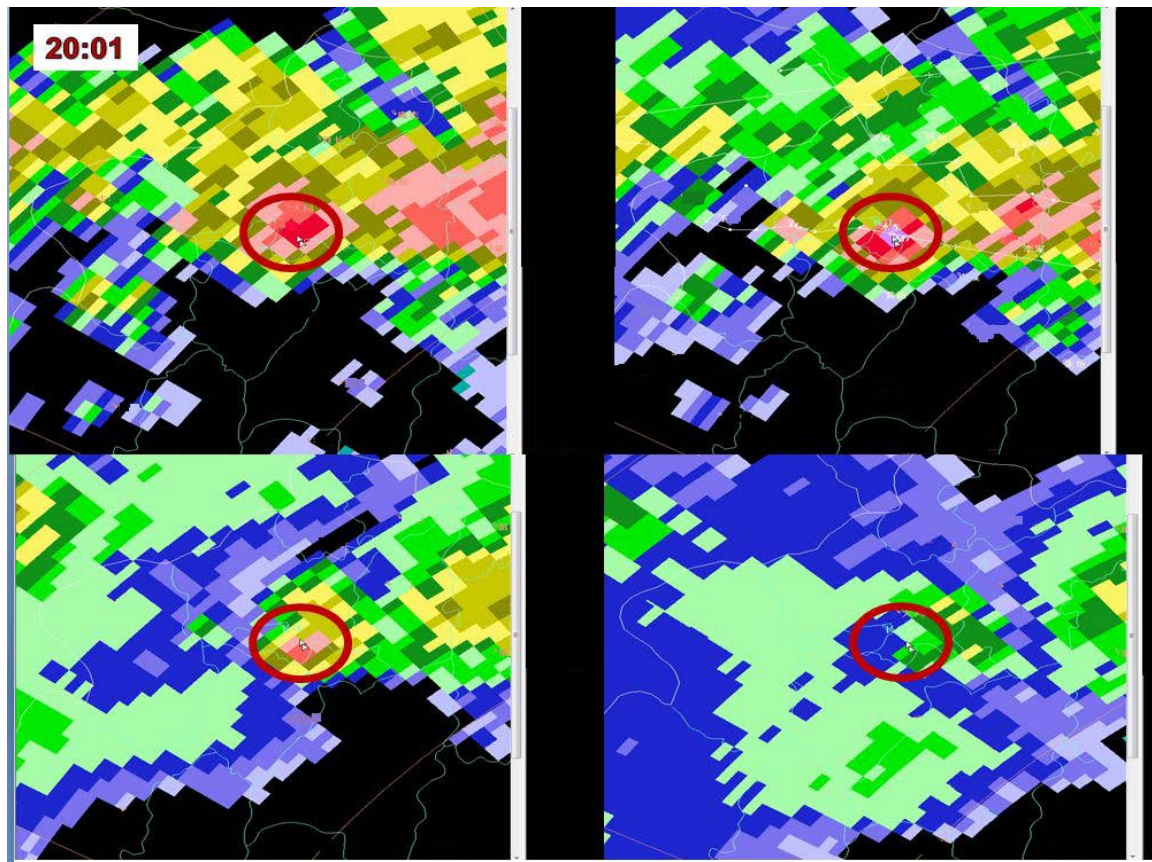

Figure $5.0 .5^{\circ}-3.3^{\circ}$ elevation angle basic reflectivity of Changting County at 20:01 on the $20^{\text {th }}$.
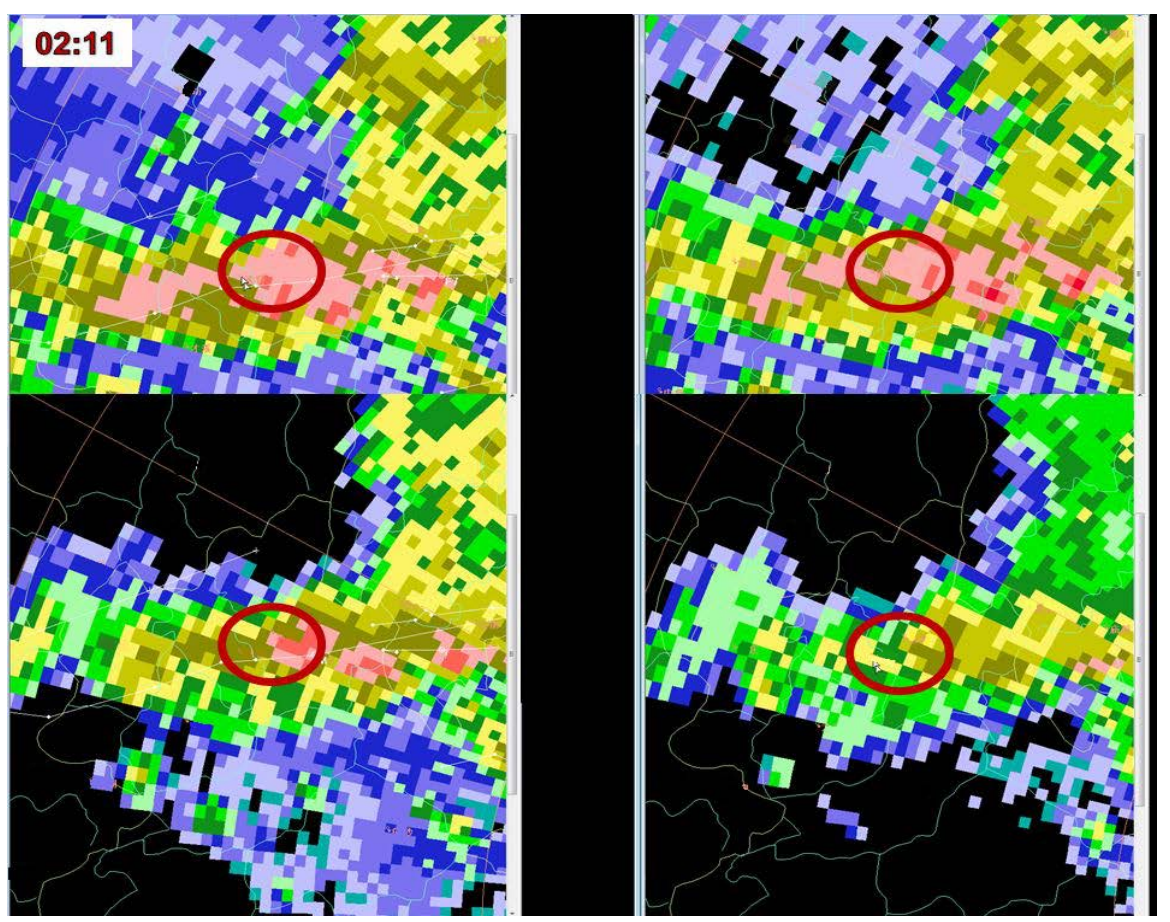

Figure 6. Basic SAR of $0.5^{\circ}-3.3^{\circ}$ elevation angle at $02: 11$ on the 21 st, Tongxian Township, Shanghang County.

Township respectively. The local precipitation reached a heavy rainstorm level. The precipitation process lasted for a short time, the accumulated rainfall was large, and the local convection developed strongly. Through the analysis of the 
weather background, automatic station data, radar echo and other data when strong convection occurs, it is found that: This strong convection process is affected by the increase of hilly terrain, cold pool, local wind convergence and strong train effect in both Changting and Shanghang. At the same time, the strong convection occurred in Hangtongxian Township of the two places is dominated by short-term heavy precipitation, which is dominated by convective warm cloud. In addition to short-term heavy precipitation, the strong convection of Changting is accompanied by strong lightning, $6-8$ thunderstorm and strong wind, which is a convective cold cloud dominated precipitation.

The reason for the inconsistent nature of the strong convection between the two places is mainly due to the inconsistent strength of the development of strong echoes (the longest strongest is $61 \mathrm{dBz}$, the upper strongest is $50 \mathrm{dBz}$ ). Moreover, in the strong convection development of Changting, there was no obvious tilt at the center of the strong echo, and the strong echo of Shanghang Tongxian Township showed a significant eastward tilt, resulting in stronger local convective weather in Changting.

\section{Acknowledgements}

This work was supported by Fujian Meteorological Bureau Open Meteorological Science Research Fund Project (2018K01).

\section{Conflicts of Interest}

The authors declare no conflicts of interest regarding the publication of this paper.

\section{References}

[1] Huang, M.J., Guo, H., Li, T.T., Xie, Y.H. and Wu, Q.S. (2017) Analysis of a Slanting Frontal Squall Line and Strong Windfall Weather. Straits Science, 6, 25-29.

[2] Tian, F.Y., Zheng, Y.G., Zhang, X.L., Zhang, T., Lin, Y.J., Zhang, X.W. and Zhu, W.J. (2018) Structure, Triggering and Maintenance Mechanism of Convective Systems during the Guangzhou Extreme Rainfall on 7 May 2017. Meteorological Monthly, 4, 469-484.

[3] Xu, C.Y., Yi, X.Y., Duan, L.Y. and Xu, L.Z. (2017) Synthetic Applications of Multi-Data to a Weak Precipitation Thunderstorm Accompanied by Disastrous Winds in Tianjin. Meteorological Science and Technology, 2, 355-363.

[4] Shao, C., Guo, P.W. and Dai, J.H. (2013) Radar and Lightning Activity Characteristics of Shanghai Short Duration Heavy Rainfall. Tropical Meteorological Journal, 29, 656-664.

[5] Feng, G.L., Qie, X.S., Yuan, Y., et al. (2007) Study on the Characteristics of Lightning Activity and Precipitation Structure in Hailstorm. Earth Science, 37, 123-132.

[6] Zheng, D., Ma, Y.J., Ma, M., et al. (2007) Simulation Study on the Influence of Atmospheric Environmental Stratification on Lightning Activity. Journal of Meteorology, 65, 622-632.

[7] Chen, M.X. and Wang, Y.C. (2012) Numerical Simulation Study of Interactional 
Effects of the Low-Level Vertical Wind Shear with the Cold Pool on a Squall Line Evolution in North China. Acta Meteorologica Sinica, 3, 371-386.

[8] Zheng, T.F., Huang, J., Wan, Q.L., Xu, H.Q., Liu, X.T. and Yu, X. (2017) Obesrvational Study on the Pre-Tropical Cyclone Squall Line of 8 August 2007 over the Coast of South China. Journal of Tropical Meteorology, 6, 933-944. 